\title{
AUTOAVALIAÇÃO E ESTÁGIO SUPERVISIONADO NA FORMAÇÃO INICIAL DOCENTE: PERSPECTIVAS CRÍTICO-REFLEXIVAS
}

\author{
NELUANA LEUZ DE OLIVEIRA FERRAGINI (UNESPAR) ${ }^{1}$ \\ http://orcid.org/0000-0001-9310-3604 \\ ÉRICA DANIELLE SILVA (UEM)² \\ https://orcid.org/0000-0003-1106-4272
}

\begin{abstract}
RESUMO: A tendência de valorização da formação e da profissionalização reflexivo-críticas de professores tem sua gênese a partir dos anos 1990. Ao buscar afastar-se da racionalidade técnica, característica dos anos 1970, a essência da perspectiva reflexiva é que o professor produza conhecimento a partir de sua prática, por meio de uma investigação teórico-reflexiva intencional e da problematização dos resultados alcançados. Neste contexto, situando-nos especificamente nas práticas formativas de professores de língua portuguesa, elegemos a autoavaliação como um gênero acadêmico e instrumento potencializador da construção do olhar crítico e da postura reflexiva. Por isso, dispensamos atenção à caracterização de suas dimensões social e verbo-visual sob aporte teórico da teoria bakhtiniana, para então lançar o olhar analítico sobre autoavaliações produzidas para o relatório final do componente de Estágio Supervisionado. Neste contexto, esta pesquisa tem como objetivo analisar a discursividade crítica mobilizada e construída na produção da autoavaliação de licenciandos do curso de Letras-Português, considerando a contribuição deste instrumento para uma formação reflexiva. A partir de um estudo quali-interpretativo, pautado em excertos das autoavaliações sobre as quais refletimos neste trabalho, e dos preceitos dialógicos, consideramos que por meio das experiências mobilizadas e analisadas pelos alunos, a construção teórica da práxis, permitiu-Ihes identificar e melhorar competências profissionais. Assim, o exercício de autoavaliar-se criticamente reforça a autonomia do professor em formação, criando um importante espaço para procedimentos que colaboram com seu processo de formação reflexiva e crítica e, consequentemente, para a construção de sua identificação profissional.
\end{abstract}

PALAVRAS-CHAVE: Estágio supervisionado curricular. Autoavaliação. Formação docente críticoreflexiva.

\section{SELF-ASSESSMENT AND INITIAL TEACHING TRAINING: CRITICAL- REFLECTIVE PERSPECTIVES}

\begin{abstract}
The tendency to value teacher training and reflexive-critical professionalization has its genesis since the 1990s. In seeking to move away from technical rationality, characteristic of the 1970s, the essence of the reflexive perspective is that the teacher produces knowledge from of its practice, through an intentional theoretical-reflective investigation and the problematization of the results achieved. In this context, placing ourselves specifically in the training practices of Portuguese teachers, we chose self-assessment as an academic genre and an instrument that potentiates the construction of critical eyes and reflective posture. For this reason, we highlight the characterization of its social and verbal-visual dimensions under the theoretical support of Bakhtin theory, to then launch the analytical look at self-assessments produced for the final report of the Supervised

${ }^{1}$ Doutora em Letras pelo Programa de Pós-Graduação em Estudos da Linguagem, da Universidade Estadual de Londrina (UEL). Professora Adjunta do curso de Letras Português, da Universidade Estadual do Paraná UNESPAR, campus de Apucarana. E-mail: neluanaferragini@gmail.com

${ }^{2}$ Doutora em Letras pelo Programa de Pós-graduação em Letras da Universidade Estadual de Maringá (UEM). Professora do Departamento de Língua Portuguesa, da Universidade Estadual de Maringá (UEM). E-mail: edsilva2@uem.br
\end{abstract}




\section{$=$ TRAMA $=$}

Internship component. In this context, this research aims at analyzing the critical discourse mobilized and built in the production of the self-assessment of undergraduate students of the Letras course, considering the contribution of this instrument to a reflective formation. Based on a qualiinterpretative study, which was guided on excerpts from the self-assessments that we reflected on in this work, and based on the dialogical precepts, we consider that through the experiences mobilized and analyzed by students, the theoretical construction of praxis, allowing them to identify and improve professional competences. Thus, the exercise of self-assessment critically reinforces the autonomy of the teacher in training, creating an important space for procedures that collaborate with his reflective and critical training process and, consequently, for the construction of his professional identification.

KEYWORDS: Supervised curricular internship. Self-evaluation. Critical-reflective teacher training.

\section{INTRODUÇÃO}

Dado o caráter multifacetado das relações entre teoria e prática que o processo formativo no ensino superior assume, sobretudo na licenciatura, cabe-lhe o papel de aprofundar os conhecimentos técnico-científicos da profissão a fim de conduzir a uma autonomia pedagógica crítica e científica e levar os licenciandos a compreender a função social na qual sua prática se insere. Tem-se, desse modo, a necessidade de localizar o processo formativo ao paradigma complexo (FREIRE; LEFFA, 2013) que, diferente do paradigma tradicional, exige conceitos e práticas marcados pela imprevisibilidade, pela contradição e pela incompletude, peculiaridades estas compatíveis à realidade sócio-histórico-cultural contemporânea.

Esse contexto é perpassado por uma arena de vozes a partir da qual desenvolvem-se embates dialógicos que podem ampliar as condições emancipatórias do sujeito e caminhar ao encontro de uma formação mais reflexiva (PIMENTA, 2012; PIMENTA; LIMA, 2012; GHEDIN, 2012; SCHÖN, 2000). Conforme destacam Pimenta e Lima (2012, p. 55), "o conhecimento e a interpretação desse real existente serão o ponto de partida dos cursos de formação, uma vez que se trata de possibilitar aos futuros professores as condições e os saberes necessários para sua atuação profissional". O estágio, segundo as autoras, deve integrar, então, todas as disciplinas do curso, além do componente específico, promovendo o desenvolvimento de uma postura investigativa, crítica, reflexiva e ética. Assim, o estágio como pesquisa acontece por meio do "estudo, [d]a análise, [d]a problematização, [d]a reflexão e [d]a proposição de soluções às situações de ensinar e aprender" (PIMENTA; LIMA, 2012, p. 55).

Sob esse enfoque, implementar práticas reflexivas que promovam a produção e construção de sentidos de si pelo próprio professor em formação permite "saber sobre si". Para Eckert-Hoff (2008, p.138), trata-se de um "saber de si que pode provocar deslocamentos na formação capazes de levar o professor a compreender-se enquanto sujeito, de forma cindida e heterogênea, já que mais do que conhecer (conteúdos) é preciso saber". Enquanto "conhecer", para a autora, está relacionado a conteúdos e ideias, "saber" passa pela experiência, pela (re)produção em exercício.

Dentre os caminhos para uma formação reflexiva e autônoma, nesta pesquisa, consideramos o gênero autoavaliação como um instrumento que possibilita a construção de um saber docente na práxis promovendo um olhar crítico ao próprio sujeito (social e históricaideologicamente situado), ao conhecimento teórico assimilado e a própria prática docente. Assim, elegemos como corpus de estudo textos autoavaliativos produzidos pelos licenciandos do curso de Letras habilitação Português, na disciplina de Estágio Supervisionado de Língua Portuguesa, em que refletem sobre o agir docente (como observadores, regentes, produtores de propostas) ao longo do processo. Situados nesse contexto, temos por objetivo analisar se a 


\section{$=$ TRAMA $=$}

discursividade crítica mobilizada e construída na produção da autoavaliação pode contribuir para uma formação mais reflexiva. Para tanto, questionamos: os procedimentos autoavaliativos na formação docente inicial podem contribuir para uma postura reflexivo-crítica mais consciente e inovadora? A compreensão da própria prática como estagiário (professor em formação) e como sujeito em atuação (professor do/no estágio) revela uma reflexão crítica do professor em formação?

\section{PROFESSOR REFLEXIVO, PROFESSOR CRÍTICO: FORMAÇÃO DOCENTE, ENSINO E APRENDIZAGEM}

No paradigma contemporâneo de profissionalização docente, considera-se tanto o professor formador quanto aquele em formação como sujeitos reflexivos "capazes de construir conhecimento através de processos interpretativos e reflexivos sobre suas experiências docentes" (MILLER, 2013, p.108). Essa busca pelo desenvolvimento da postura crítica, reflexiva e ética é perpassada pela emergência de atividades formativas, sobretudo na pesquisa participativa, de caráter exploratório por meio de narrativas, entrevistas e diários. Uma das maiores contribuições desses gêneros acadêmicos apontadas por Miller (2013, p. 112) é o foco da "agentividade dos participantes e nos processos de conscientização individualmente vivenciados pelos membros dos grupos de investigação".

A cultura reflexiva pode ser compreendida como uma prática que acontece em diversificados momentos do agir docente. Donald Schön (1992) compreende três momentos: a reflexão na ação, a reflexão sobre a ação e a reflexão sobre a reflexão na ação. A reflexão na ação elucida os saberes que orientam o agir docente no momento de sua prática, isto é, quando o professor reflete sobre a ação presente. É um "diálogo com a situação, no exato momento em que os imprevisíveis e incertos fenômenos são encontrados" (VALADARES, 2012, p. 217). O olhar crítico para a própria atuação permite a descrição consciente das ações, ampliando a compreensão de todos os fatores que influenciam o agir docente, o que pode conduzir a novas estratégias docentes.

Na reflexão sobre a ação, o agir docente é observado em momento posterior à prática e consiste na reconstrução mental da ação, com o intuito de analisar retrospectivamente o próprio agir, mas sob uma ótica externa. Ao reconstruir a pretérita ação, permite-se observar os caminhos assumidos que orientaram a prática, avaliando tais ações, bem como elaborar estratégias para situações futuras. Consequentemente, criar novas estratégias e pensar em caminhos outros conduz o professor a realizar o processo de reflexão sobre a reflexão na ação; "Esse tipo de reflexão leva o professor a desenvolver novos raciocínios, novas formas de pensar, de compreender, de agir e equacionar problemas" (FONTANA; FÁVERO, 2013, p. 3-4).

Já para Sacristán (1988 apud LIBÂNEO, 2012), os processos reflexivos compreendem duas fases: a prévia (planejamento) e a posterior (revisão/crítica). Para o estudioso, a reflexão e a investigação na ação não significam refletir na ação, visto que "a principal característica do pensamento é o distanciamento dos fenômenos, precisamente para entendê-los melhor" (LIBÂNEO, 2012, p. 81). Sob esse viés, os três níveis de reflexividade definidos por Sacristán são sintetizados por Libâneo (2012, p. 82):

O $1^{\circ}$ nível corresponde a um distanciamento da prática para vê-la, entendê-la, avaliá-la. Refere-se ao mesmo tempo à prática e a apreensão cognitiva da prática, a partir do fazer cotidiano, do senso comum. O professor atual de acordo com suas teorias subjetivas (senso comum, representações), ou seja, o pensamento do professor é saber deduzido de suas ações. O $2^{\circ}$ nível é o que incorpora a ciência ao senso comum. $\mathrm{O} 3^{\circ}$ nível é a reflexão sobre as práticas da reflexão, a 


\title{
$=$ TRAMA $=$
}

metarreflexividade, tarefa para a qual se trata de pensar as características dos dois níveis anteriores de reflexividades.

Ao cotejarmos os entendimentos de reflexividade para Schön e Sacristán, elucidamos os caminhos que percorremos na busca pela compreensão dos processos de reflexão, o que não limita a existência de outros entendimentos e outras comparações. Diante dos posicionamentos ilustrados, adotamos os pressupostos de Sacristán, por corroborarmos com o pesquisador quanto à ideia de que "o distanciamento nos permitirá utilizar toda a cultura para racionalizar as ações, que é o que dá sentido à educação e à formação do professorado" (SACRISTÁN, 1998 apud LIBÂNEO, 2012, p. 82), ademais, porque o momento de reflexão sob o qual se volta nosso olhar compreende um processo reflexivo posterior à atuação em sala.

Partindo dos pressupostos arrolados, a concepção crítica de reflexividade, segundo Libâneo (2012), promove uma reflexão emancipadora e uma autonomia intelectual. Para tanto, o autor postula que o professor deve desenvolver simultaneamente três capacidades, a saber:

\begin{abstract}
a primeira, de apropriação teórico-crítica das realidades em questão considerando os contextos concretos da ação docente; a segunda, uma apropriação de metodologias de ação, de formas de agir, de procedimentos facilitadores do trabalho docente e de resolução de problemas de sala de aula. O que destaco é a necessidade da reflexão sobre a prática a partir da apropriação de teorias como um marco para as melhorias das práticas de ensino, em que o professor é ajudado a compreender o seu próprio pensamento e a refletir de modo crítico sobre sua prática e, também, a aprimorar seu modo de agir, seu saberfazer, internalizando também novos instrumentos de ação. A terceira, é a consideração dos contextos sociais, políticos, institucionais na configuração das práticas escolares (LIBÂNEO, 2012, p. 83).
\end{abstract}

O saber de si é um autoconhecimento que permite a emancipação do educador, ou melhor, a autonomização docente, "não sendo mais um agente formador de mão de obra para o mercado, mas o arquiteto da nova sociedade, livre e consciente de seu projeto político" (GHEDIN, 2012, p. 156). Isso posto, destacamos ancoradas em Zeichner (1992 apud VALADARES, 2012) que não basta promover a prática reflexiva, é preciso avaliar como e sobre o que se reflete. Do mesmo modo, é preciso que a reflexão resulte em um novo agir, afinal "a reflexão não é o fim em si mesma, mas um meio possível e necessário para que possamos operar um processo de mudança no modo de ser da educação" (GHEDIN, 2012, p. 169).

$\mathrm{Na}$ esteira da produtividade dessa tendência formativa, mobilizamos a autoavaliação como um gênero acadêmico e instrumento que pode contribuir para a construção do olhar crítico e da postura reflexiva. Por isso, dispensamos atenção à caracterização de suas dimensões social e verbo-visual, definições estas que serão o foco da próxima seção.

\section{AUTOAVALIAÇÃO COMO UMA PRÁTICA PEDAGÓGICA PARA A FORMAÇÃO DOCENTE}

Autoavaliar-se é uma prática recorrente em domínios cotidianos que adentrou esferas mais complexas adequando-se a discursos secundários. No intuito de compreender a autoavaliação como um gênero pertinente ao campo da formação docente, elencamos, a partir dos conceitos bakhtinianos, suas dimensões social (contexto extraverbal) e verbal (aspectos verbo-visuais).

A dimensão social compreende os fatores extraverbais a partir dos quais a autoavaliação emerge. Organizamos, no quadro abaixo, os aspectos contemplados nesta categoria: 


\section{$=$ TRAMA $=$}

Quadro 1 - A dimensão social do gênero autoavaliação.

\begin{tabular}{|c|c|c|}
\hline \multicolumn{3}{|c|}{ DIMENSÃO SOCIAL DO GÊNERO AUTOAVALIAÇÃO } \\
\hline $\begin{array}{l}\text { Elementos } \\
\text { contextuais }\end{array}$ & $\begin{array}{l}\text { Perguntas para recuperar } \\
\text { o contexto de produção }\end{array}$ & $\begin{array}{l}\text { Respostas que podem recuperar a dimensão } \\
\text { social do gênero e do enunciado em análise }\end{array}$ \\
\hline \multirow{5}{*}{ 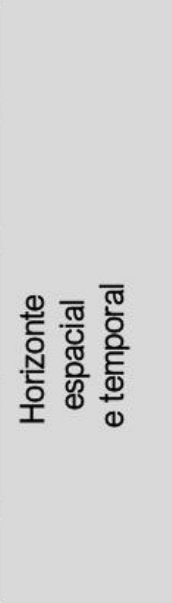 } & $\begin{array}{l}\text { Em que locais costuma } \\
\text { ser produzido? }\end{array}$ & $\begin{array}{l}\text { Nas instituições de ensino, como escola e } \\
\text { universidades. }\end{array}$ \\
\hline & $\begin{array}{l}\text { Qual é o campo social de } \\
\text { produção? }\end{array}$ & $\begin{array}{l}\text { O campo social de produção da autoavaliação é } \\
\text { o acadêmico/escolar. }\end{array}$ \\
\hline & $\begin{array}{l}\text { Em quais situações } \\
\text { costuma ser produzido? }\end{array}$ & $\begin{array}{l}\text { Costuma ser produzido como uma atividade } \\
\text { acadêmica/escolar avaliativa, geralmente por } \\
\text { solicitação docente. }\end{array}$ \\
\hline & $\begin{array}{l}\text { Qual é o veículo de } \\
\text { circulação? }\end{array}$ & $\begin{array}{l}\text { Papel (trabalho impresso/manuscrito) ou e-mail } \\
\text { (trabalho enviado pela internet). }\end{array}$ \\
\hline & $\begin{array}{l}\text { Qual é o suporte de } \\
\text { circulação? }\end{array}$ & $\begin{array}{l}\text { As autoavaliações podem circular por meio } \\
\text { impresso ou como uma tarefa digital. }\end{array}$ \\
\hline \multirow{2}{*}{ 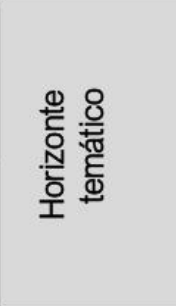 } & $\begin{array}{l}\text { Qual é o seu tema ou } \\
\text { conteúdo temático? }\end{array}$ & $\begin{array}{l}\text { O tema é variável, podendo abordar a } \\
\text { desenvoltura do sujeito em um trabalho/uma } \\
\text { prática, como aluno, como estagiário, etc. }\end{array}$ \\
\hline & Com que finalidade? & $\begin{array}{l}\text { A finalidade do gênero é manifestar uma reflexão } \\
\text { crítica sobre uma característica ou ação ou } \\
\text { atividade do próprio produtor. }\end{array}$ \\
\hline \multirow{5}{*}{ 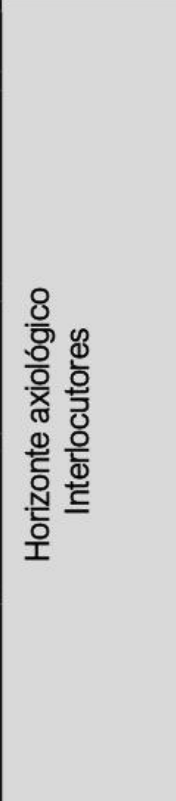 } & Quem é que produz? & É produzido pelos estudantes. \\
\hline & $\begin{array}{l}\text { Qual é o papel social do } \\
\text { autor? }\end{array}$ & $\begin{array}{l}\text { O autor ocupa o papel social de autocrítico, que } \\
\text { além da preocupação em apresentar uma } \\
\text { avaliação sobre si mesmo também revela sua } \\
\text { valoração a respeito do que e como expõe. }\end{array}$ \\
\hline & Para quem é produzido? & $\begin{array}{l}\text { Como destinatário, a autoavaliação é produzida, } \\
\text { geralmente, para os professores que as } \\
\text { solicitam. }\end{array}$ \\
\hline & $\begin{array}{l}\text { Que imagem o autor faz de } \\
\text { seu interlocutor? }\end{array}$ & $\begin{array}{l}\text { Possivelmente de alguém que espera uma } \\
\text { escritura altamente reflexiva, subjetiva e } \\
\text { devidamente justificada. }\end{array}$ \\
\hline & $\begin{array}{l}\text { Qual é a atitude valorativa } \\
\text { dos participantes? }\end{array}$ & $\begin{array}{l}\text { O autoavaliado valora em seus textos aspectos } \\
\text { que ele considera relevantes em seu agir e em } \\
\text { sua personalidade. Já o professor valora o nível } \\
\text { de reflexão e o grau de criticidade do } \\
\text { licenciando. }\end{array}$ \\
\hline
\end{tabular}

Fonte: Adaptado pelas autoras do estudo de Costa-Hübes, 2017.

Quanto à dimensão verbo-visual, indissolúvel da dimensão social, destacamos três elementos constitutivos de um gênero, conforme Bakhtin (2003): conteúdo temático, estilo e construção composicional. Composicionalmente, a autoavaliação consiste em um textoenunciado em prosa (escrito ou oral), de extensão relativamente breve, visto sintetizar habilidades e/ou conhecimentos adquiridos, algumas vezes guiada por uma sequência de 


\section{$=$ TRAMA $=$}

questões norteadoras. Em alguns casos, pode ser finalizada com uma nota atribuída pelo sujeito que se avalia.

Dependendo do contexto, as autoavaliações podem variar o objeto de análise. Em domínios discursivos mais complexos, uma autoavaliação profissional, por exemplo, costuma elencar qualidades e limitações daquele que se avalia. Na escola ou na universidade, pode ter como foco a aprendizagem, o desempenho, uma atividade desenvolvida ou uma série delas, a própria prática como futuro profissional, entre outros objetos. A temática envolve sempre o processo de avaliar a si mesmo.

No tocante ao estilo, tem-se o uso da primeira pessoa do singular, quando a autoavaliação é individual; e primeira pessoa do plural, caso se tratar de um grupo que se avalia. Recorre-se a uma linguagem mais elaborada, compatível ao discurso acadêmico/escolar, contudo sem a exigência de um rigor normativo altamente de prestígio. Também não são solicitados conceitos teórico-práticos, mas requer um olhar atento, analítico e crítico ao objeto em análise, bem como posicionamentos justificados e argumentos que sustentem um posicionamento, aspecto tipológico que a insere na ordem do argumentar.

Em síntese, a autoavaliação se constrói dialogicamente na interação verbo-social, que atribui ao outro e ao tema papel tão importante quanto o de quem enuncia. Contudo, sobressaise no gênero outra característica dialógica: do sujeito com o seu próprio eu. Nas palavras de Bakhtin (2016, p. 98), "ao me objetivar (isto é, ao me colocar para fora de mim mesmo) ganho a possibilidade de uma relação autenticamente dialógica comigo mesmo". Como processo metacognitivo, a autoavaliação propicia a tomada de consciência por meio do olhar crítico daquilo que fora produzido pelo sujeito, permitindo-lhe olhar para os próprios erros e, a seu modo, confrontar-se com os obstáculos.

A autoavaliação como uma ferramenta formativa cria espaço para inverter as clássicas finalidades da avaliação, descentralizando a função do professor como responsável unilateral pela aprendizagem, bem como convida o aprendiz a refletir sobre seu processo de aquisição de conhecimentos, sua aprendizagem. Num contexto de aquisição de saberes, a autoavaliação "acompanha todo o desenvolvimento da ação. Depois, fala-se de autocontrole, uma espécie de olhar crítico sobre o que se faz enquanto se faz, guiado por seu próprio sistema interno de pilotagem" (NUNZIATI, 1990, p. 53). Nesse sentido, favorece o desenvolvimento do sujeito como aprendente e como ser social, visto a autoavaliação ser "fundamental tanto para o desenvolvimento escolar do educando, quanto para a evolução pessoal do indivíduo, pois ela constitui uma capacidade de reflexão, de objetivação, de ação e de motivação para um progresso pessoal" (MELO, 2009, p. 40).

Elencados os pressupostos que norteiam nossa compreensão da autoavaliação, passamos a discutir como a autoavaliação pode contribuir para a contextura da pesquisa para, em seguida, expor as considerações analítico-interpretativas.

\section{A CONTEXTURA DA PESQUISA}

Ao mobilizarmos a dimensão social do gênero autoavaliação para investigar a viabilidade deste instrumento para a formação crítico-reflexiva, ponderamos que o autoconhecimento não resulta unicamente na avaliação de si mesmo, já que a autorreflexão implica conhecer-se como sujeito que interage com um contexto maior e que é, também, desse contexto. Assim, a autocrítica pode/deve ampliar a compreensão do mundo ao redor do sujeito, o qual é compreendido nesta pesquisa como sujeito ideológico e responsivamente constituído. A partir dos pressupostos teórico-metodológicos da formação reflexiva, do sujeito constituído 
ideológica e, por isso, repleto de valores e de juízos, e da linguagem como meio de interação, organizamos as categorias e os critérios de análise sob a forma de quadro, tal como segue:

Quadro 2 - Categorias e critérios de análise.

\begin{tabular}{|c|c|c|}
\hline \multicolumn{3}{|c|}{$\begin{array}{c}\text { ASPECTOS DO GÊNERO AUTOAVALIAÇÃO QUE CONTRIBUEM PARA O } \\
\text { DESENVOLVIMENTO CRÍTICO-REFLEXIVO }\end{array}$} \\
\hline \multirow{6}{*}{$\begin{array}{l}\text { Compreensão } \\
\text { dialógica da } \\
\text { interação } \\
\text { mediada pelo } \\
\text { gênero } \\
\text { autoavaliação }\end{array}$} & \multirow{3}{*}{$\begin{array}{l}\text { Quanto à } \\
\text { dimensão } \\
\text { social }\end{array}$} & $\begin{array}{l}\text { - O aluno compreende o papel social que assume ao se } \\
\text { autoavaliar ou vê apenas como uma tarefa acadêmica? }\end{array}$ \\
\hline & & $\begin{array}{l}\text { - A finalidade do gênero reflete-se na escritura do } \\
\text { licenciando? }\end{array}$ \\
\hline & & $\begin{array}{l}\text { - A autoavaliação apresenta uma valoração positiva } \\
\text { ou negativa para o professorando? }\end{array}$ \\
\hline & \multirow{3}{*}{$\begin{array}{l}\text { Quanto à } \\
\text { dimensão } \\
\text { verbal }\end{array}$} & $\begin{array}{l}\text { - O educando retoma as ações e rememora as } \\
\text { experiências e atividades por ele desenvolvidas? }\end{array}$ \\
\hline & & $\begin{array}{l}\text { - Há uma busca por compreender as ações realizadas } \\
\text { ponderando os aspectos que guiaram as escolhas? }\end{array}$ \\
\hline & & $\begin{array}{l}\text { - Os julgamentos de autocrítica são fundamentados e } \\
\text { justificados? }\end{array}$ \\
\hline \multirow{2}{*}{$\begin{array}{l}\text { Conhecimentos } \\
\text { teórico- } \\
\text { metodológicos da } \\
\text { formação } \\
\text { docente inicial }\end{array}$} & Saberes & $\begin{array}{l}\text { - Quais saberes são valorados pelo licenciando ao refletir } \\
\text { sua atuação no estágio? } \\
\text { - Os saberes sistematizados da graduação são } \\
\text { acionados crítica e conscientemente pelo } \\
\text { professorando? }\end{array}$ \\
\hline & Experiências & $\begin{array}{l}\text { - De que forma as experiências são avaliadas pelo sujeito } \\
\text { em formação? } \\
\text { - Que tipo de experiências são ressaltadas? } \\
\text { - O licenciando tem consciência da interferência (ou não) } \\
\text { dessas experiências em sua prática? }\end{array}$ \\
\hline \multirow{3}{*}{$\begin{array}{l}\text { Compreensão } \\
\text { dos sentidos que } \\
\text { instituem o sujeito }\end{array}$} & \multirow[t]{2}{*}{$\begin{array}{l}\text { Conhecimento } \\
\text { de si mesmo }\end{array}$} & $\begin{array}{l}\text { - Como o professorando compreende-se como } \\
\text { professor? } \\
\text { - Qual avaliação/crítica faz de sua própria práxis? }\end{array}$ \\
\hline & & $\begin{array}{l}\text { - Que fatores o acadêmico considera importantes para } \\
\text { sua constituição docente? }\end{array}$ \\
\hline & $\begin{array}{l}\text { Conhecimento } \\
\text { de si como } \\
\text { sujeito situado } \\
\text { em um } \\
\text { contexto maior }\end{array}$ & $\begin{array}{l}\text { - De que forma, os aspectos externos e os internos } \\
\text { interferem na forma como o licenciando compreende } \\
\text { sua prática docente? O professor em formação } \\
\text { demonstra consciência de fatores externos à sua } \\
\text { prática? Como avalia esses fatores? } \\
\text { - As reflexões preveem um novo agir? } \\
\text { - No processo reflexivo, há valorações e entonações do } \\
\text { "eu" e do "outro"? } \\
\text { - Há juízos de valor social compartilhados no processo } \\
\text { reflexivo? } \\
\text { - O professor em formação compreende-se como um } \\
\text { sujeito social e dialógico, ativamente responsivo? }\end{array}$ \\
\hline
\end{tabular}

Fonte: As autoras. 


\section{$=$ TRAMA $=$}

Contextualizamos, então, a constituição de nosso corpus. No terceiro e quarto ano, os licenciandos do curso de Letras habilitação Português realizam vinte horas de observação e de regência nas turmas de Ensino Fundamental II e Médio, respectivamente. A preferência é que o Estágio aconteça sempre em duplas, porém, às vezes se torna necessária a formação de trios. Dentre as atividades avaliativas solicitadas, os professores em formação devem produzir, individualmente, ao término do ano letivo, um dossiê final composto por (a) caracterização do ambiente escolar; (b) relatórios reflexivos de observação e de regência; (c) planos de trabalho docente (PTD) ou planos de aula; e (d) a avaliação do estágio, que compreende uma avaliação geral do processo e uma autoavaliação. Para a autoavaliação, é oferecido aos alunos um roteiro específico com algumas categorias e indagações para auxiliá-los no processo de autocrítica. As categorias destacadas são: responsabilidade; qualidades pessoais relativas à atuação docente; dificuldades relativas à atuação docente; relacionamento; preparo social; desempenho, experiência e formação. Ressaltamos que as questões não engessam o processo de escritura, visto que se trata de apenas de um parâmetro para o desenvolvimento do texto.

O corpus de nossa pesquisa é composto pelas autoavaliações produzidas para os relatórios finais. Ao todo, são 52 relatórios; 26 produzidos em 2017, quando os acadêmicos cursaram o $3^{\circ}$ ano, e 26 em 2018, quando cursaram o $4^{\circ}$ ano. Para este estudo, selecionamos 20 autoavaliações ${ }^{3}, 10$ produzidas no $3^{\circ}$ ano e 10 no $4^{\circ}$ ano, pelos mesmos alunos. Ao elegermos as produções das duas etapas do estágio podemos ponderar se houve um aprofundamento reflexivo no segundo momento dada a experiência teórico-metodológica construída em mais um ano do curso e em experiências de estágio distintas, ou mesmo se houve uma apropriação do gênero autoavaliação.

\section{FORMAR PARA REFLETIR, REFLETIR PARA CONHECER, CONHECER PARA TRANSFORMAR}

Apoiadas metodologicamente na perspectiva quali-interpretativista, procuramos observar se o discurso do professor em formação compreende as relações sociais e seu papel neste contexto de modo a resultar em uma produção discursiva socioideológica por meio do gênero discursivo autoavaliativo. Dito de outro modo, buscamos compreender se uma proposta autoavaliativa pode contribuir para uma formação docente mais reflexiva e crítica.

Isso posto, nossas considerações analítico-interpretativa assumem como princípio organizador os critérios elencados na seção anterior, quanto à compreensão: a) dialógica da interação mediada pelo gênero autoavaliação; b) dos conhecimentos teórico-metodológicos da formação docente inicial; e c) dos sentidos que constituem o sujeito.

No que concerne à compreensão dialógica da interação mediada pelo gênero, o entendimento do objetivo do gênero solicitado alinha-se à perspectiva reflexiva no tocante ao saber a razão de produzi-lo. Em linhas gerais, no corpus em questão, a verbalização da percepção das finalidades discursivas do gênero enquanto estratégia avaliativa é praticamente inexistente. Apenas no enunciado da licencianda Cátia4 ${ }^{4}$, podemos observar explicitamente uma das finalidades: "A autoavaliação é um processo que nos permite perceber o que há de melhor

\footnotetext{
${ }^{3} \mathrm{O}$ estudo do corpus realizou-se por meio de amostragem. Por se tratar de uma pesquisa de cunho qualiinterpretativista não foi possível uma amostragem ampla, por isso nos limitamos a pouco mais que um terço do total de autoavaliações. Para chegar a esse quantitativo, o primeiro critério foi partir dos textos elaborados no terceiro ano. Depois, elegemos arbitrariamente a autoavaliação de um integrante de cada dupla ou trio formada durante o terceiro ano do curso, o que nos permitiu uma amostragem parcial de todas as equipes. No quarto ano, apenas mantivemos as autoavaliações dos mesmos estudantes já selecionados, mesmo que não formassem as mesmas duplas ou trios no ano subsequente.

${ }^{4}$ Uma vez que a pesquisa segue os padrões de ética acadêmica, atribuímos nomes fictícios aos acadêmicosautores dos trechos citados. Ressaltamos que os alunos participantes foram previamente informados da pesquisa e assinaram o Termo de Consentimento Livre e Esclarecido.
}

Revista Trama | Volume 17 | Número 41 | Ano 2021 | p. 73-87 | e-ISSN 1981-4674 


\section{$=$ TRAMA $=$}

em nós mesmos e aquilo que precisa necessariamente ser melhorado" ( $4^{\circ}$ ano, grifos nossos). Assim, considerar que o gênero possibilita essa percepção indica que, para além de uma prática avaliativa, esse sujeito tem a consciência da oportunidade de refletir sobre si mesmo, sobre as possibilidades de mudança e, consequentemente, sobre seu (futuro) agir docente. Com a apropriação da finalidade do gênero autoavaliativo, consideramos que a estudante, ao "definir" tal finalidade, avalia reflexivamente o gênero, emitindo um juízo de valor, ou seja, ela apresenta uma posição valorativa em relação à atividade, atuando responsivamente quanto à proposta desenvolvida.

No tocante aos conhecimentos teórico-metodológicos da formação docente inicial, em que podemos observar os saberes e as experiências acionados pelos futuros formadores, os saberes situam-se mais no âmbito do domínio de conteúdos, do que no de saberes didáticos, visto os licenciandos evidenciarem relatos da preparação do conteúdo a ser ministrado, o qual parece algo "extra", não remetendo ao que já foi estudado na graduação. Sobre isso, destacamos a colocação da aluna Cátia, no relatório do $3^{\circ}$ ano, que explica que "Para aplicar as aulas da regência tive que buscar alguns conteúdos externos para que a explicação fosse mais eficiente" (grifos nossos). Já Viviane, também no $3^{\circ}$ ano, ressalta: "Horas planejando aula, atividades, dinâmicas, slides, etc., horas lendo para compreender o que ensinar e horas em uma sala de aula. Ser professor requer coragem, inteligência e humildade, não é apenas um transmitir o que se sabe esperando que o próximo entenda como eu entendi" (grifos nossos). Elena, por sua vez, na autoavaliação do $4^{\circ}$ ano, explica que "Por conta de toda essa responsabilidade em "fazer acontecer", confesso que não fiz muitas leituras extras para a explicação e não estava tão preparada" (grifos nossos).

A questão dos saberes incide na apropriação do conhecimento como se esse saber por si só fosse suficiente ao agir docente. Distinguindo-se sutilmente, o discurso de Viviane amplia essa visão, mesmo que implicitamente, ao saber didático, afinal, ensinar "não é apenas um transmitir o que se sabe esperando que o próximo entenda". A compreensão de que "saber alguma coisa não é mais suficiente, é preciso também saber ensinar" (TARDIF, 2014, p. 44), em nossa interpretação, é avaliada com uma apropriação crítico-reflexiva do agir docente. Ao pontuarem saberes que "definem" o agir docente, as acadêmicas revelam aspectos que para elas são mais valorados, no momento, quanto à profissão.

Ainda no campo dos conhecimentos teórico-metodológicos, as experiências ressaltadas pelos licenciandos dizem respeito, de modo mais geral, às atividades próprias ao estágio, como as etapas de observação e de regência. De forma mais específica, pontuamos a mudança de papéis nas fases do estágio de observação/participação e de regência, a partir da reflexão de Viviane ( $3^{\circ}$ ano): "Desde a observação até a regência passamos por uma transformação: de espectador para o ator. Quando observamos, apenas julgamos com nossos pré-conceito e opiniões, mas quando estamos no comando da sala de aula é que sentimos o quão difícil é essa realidade" (grifos nossos).

O trecho ilustra um posicionamento racionalizado da crítica ao outro e a si mesmo. Ao assumir a posição de "observadora" da aula alheia (estágio de observação), a professora em formação pondera ser uma atividade mais fácil em relação à regência. Enquanto observa, limitase a avaliar a prática do professor mais experiente, contudo, demonstra que assumir o papel do outro não é uma tarefa simples. Tal apontamento revela que a observação é uma atividade com limitações, não sendo possível avaliar o tempo de preparação da aula, o domínio do conteúdo, a formação do profissional, inclusive o estado emocional em que se encontra o docente. Já como regente, os aspectos ampliam-se, por isso pode-se correlacionar elementos que ultrapassam o momento da aula. Sob essa ótica, o licenciando "não aborda um problema como 


\section{$=$ TRAMA $=$}

cópia de uma teoria geral, e sim utilizando a intuição, analogias e metáforas, ou seja, usa seu conhecimento tácito já automatizado devido a reflexões e experimentações anteriores" (VALADARES, 2012, p. 217).

Os saberes e experiências acionados no processo reflexivo dos licenciandos como conhecimentos teórico-metodológicos da formação docente são expostos, de modo generalizado e de forma não sistematizada, o que revela, por vezes, uma dificuldade em relacionar os conhecimentos acadêmicos às experiências, não os transformando em saberes. $\mathrm{Na}$ contramão desse aspecto, acreditamos que a compreensão de um gênero discursivo que visa promover a autocrítica pode conduzir a uma interação mais pró-ativa, já que no processo de escrita o estudante assume a posição discursiva de enunciador e situa socialmente seu discurso, expondo, desse modo, seus valores ideológicos ao refletir e operar sobre a língua. Ademais, observamos que os licenciandos, ao ponderarem sobre a própria práxis, têm consciência das ações que contribuíram positiva e/ou negativamente para suas ações, permitindo-Ihes (re)pensar o próprio agir docente, uma consciência evocada no processo de escritura sobre si.

Por último, em relação aos sentidos que constituem o sujeito, as autoavaliações possibilitam compreender expectativas, anseios e inseguranças quanto à disciplina e quanto à própria prática permitindo-nos, como docentes, observar, quiçá entender, como essas emoções podem interferir na maneira como os licenciandos interagem com as etapas desenvolvidas em um componente curricular do curso voltado para a preparação e para a experiência docente em sala de aula. Nas produções do $3^{\circ}$ ano, notamos que esses sentimentos são despertados pela "novidade" da disciplina. Para a maioria dos graduandos, a experiência do estágio é a primeira oportunidade de assumir o papel de professor in loco, de vivenciar a sala de aula sob outra perspectiva. Dentre as emoções e sentimentos elucidados, em algumas autoavaliações são manifestadas valorações sobre sua própria prática, das quais destacamos, primeiramente, a de Benício ( $3^{\circ}$ ano): "[...] e diante da ideia que tinha do Estágio - de que era chato, pensei que seria um fracasso ou que não seria nada demais, apenas mais uma obrigatoriedade do curso. No entanto, a experiência foi transformadora. Parecia que eu fazia aquilo há anos, pois me senti super confortável". Nota-se que Benício verbaliza o caráter avaliativo e obrigatório da disciplina de estágio, colocando em cena as expectativas construídas desde o início do curso para esta etapa e avaliada positivamente após a atividade de regência.

Esse processo foi destacado também pela aluna Paula na autoavaliação produzida no $3^{\circ}$ ano, quando destaca que "Ao meu ponto de vista, superei as minhas expectativas, não fui tudo o que queria, porém consegui fazer o que estava no cronograma, com uma execução satisfatória, os erros ocorridos foram pela falta de experiência então relevantes ao meu ver". Já no $4^{\circ}$ ano, Paula relata: "Ao meu ponto de vista, superei as minhas expectativas, não fui tudo o que queria, porém consegui fazer o que estava no cronograma, com uma execução satisfatória, os erros ocorridos foram pela falta de experiência então relevante a meu ver, acredito ter uma boa didática, uma boa postura, mas insegura ainda quanto ao conteúdo, por ter uma péssima memória e não falta de esforço. Sempre procurei auxiliar as colegas de equipe dividindo as tarefas, sempre procurando conteúdos extras para estudar" (grifos nossos). Para a licencianda, os erros são ocasionados pela falta de experiência, por não dominar o conteúdo. Mesmo avaliando positivamente sua superação, incluindo em seu julgamento "ter uma boa didática", Paula reconhece que "ainda" tem problemas com o conteúdo por falta de memória (aspecto negativo).

Julgamos essas colocações relevantes para o processo de reflexão da professoranda, uma vez que ao desmembrar a colocação mais generalista "execução satisfatória" ( $3^{\circ}$ ano), 


\section{$=$ TRAMA $=$}

feita após a primeira experiência, Paula especifica outros três aspectos: "ter boa didática", "boa postura" e "domínio de conteúdo" ( $4^{\circ}$ ano). Trata-se, sob nossa análise, de um refinamento do conhecimento de si mesmo, o que demonstra um crescimento importante no aspecto críticoreflexivo, em que há a busca por compreender os fatores que constituem a própria identificação docente, afinal "Olhar o que estamos fazendo, refletir sobre os sentidos e os significados do fazer pedagógico é, antes de tudo, um profundo e rigoroso exercício de compreensão de nosso próprio ser" (GHEDIN, 2012, p.165).

Algumas avaliações também demonstraram que, apesar de julgarem negativamente o próprio desempenho, não foi desconsiderada a possibilidade de um novo agir no estágio subsequente, como no relato de Eduardo ( $3^{\circ}$ ano): "Não me desenvolvi como eu esperava, mas acredito que no ano que vem estarei mais preparado". Já na autoavaliação seguinte, o mesmo aluno, apesar de não explicitar se superou as expectativas ou se se sentiu melhor preparado do que no ano anterior, explicita, de modo similar a estratégia autoavaliativa de Paula, elencando alguns critérios: "desempenhei a minha função dentro das minhas condições, visto que há outras atividades que devem ser desenvolvidas além do estágio"; "Sempre compareci com antecedência no local de estágio"; "agi com responsabilidade e desenvolvi os trabalhos conforme eram estabelecidos"; "procurei por atividades e metodologias que atraísse mais o aluno e assim facilitasse a sua interpretação" e "a minha timidez me prende um pouco e isso acaba prejudicando no meu desenvolvimento como professor". Dos critérios pontuados, destacamos a justificativa dada ao desempenho dentro das condições, uma vez que, nos cursos de licenciaturas, sobressaem-se estudantes que acumulam estudo e jornadas de trabalho para seu próprio auxílio financeiro, às vezes, de sua família também. Não que isso seja um fator que diminua a qualidade profissional desses estudantes, mas é um fato limitador do tempo de dedicação ao estudo, ou seja, um aspecto social que, na visão do licenciando, interfere em sua atuação.

Alguns licenciandos buscaram justificar as dificuldades durante a atuação em sala de aula. Os itens recorrentes são a falta de experiência, a ansiedade, a timidez, a dificuldade para didatizar o conteúdo e para chamar a atenção dos alunos, além das falhas no domínio do conteúdo, pois dependiam muito de anotações para as explicações. Apesar disso, os licenciandos consideraram que não houve prejuízo no conteúdo/aprendizado dos alunos. Julgamos relevante apontar que algumas dessas dificuldades vão sendo atenuadas ao longo do estágio, como observamos na autoavaliação de Cecília ( $3^{\circ}$ ano): "Apesar de todas as dificuldades, penso que ao longo das aulas alguns aspectos, como a timidez, foram melhorados".

Determinadas colocações nas autoavaliações do $3^{\circ}$ ano indicam o reconhecimento de que a experiência contribuiu para a etapa seguinte do estágio (estágio do $4^{\circ}$ ano), como nas colocações de Eduardo mencionadas anteriormente. Destacamos também a de Elena ( $\left.3^{\circ} \mathrm{ano}\right)$ : "Apesar de toda a "turbulência", o estágio contribuiu para meu crescimento profissional e me preparou para o próximo ano" (grifos nossos); a de Milena ( $3^{\circ}$ ano): "Creio que ainda tenho muitas coisas que podem ser melhoradas, principalmente na próxima etapa que serão com alunos/as maiores, espero poder me adaptar melhor a eles/as durante o estágio do ensino médio. Um dos aspectos a serem melhorados é a maneira de conduzir a aula, necessito focar mais para evitar que os/as alunos/as se dispersem, além de obter segurança do conteúdo sem precisar utilizar folhas a todo o tempo. Com a prática [sic.] é possível se aprimorar e melhorar cada vez mais, afirmo ser esta uma das chaves que contribui para um professor de qualidade (grifos nossos); e, ainda, a de Viviane ( $3^{\circ}$ ano): "Desse modo, acredito que ainda tenho muito a 


\section{$=$ TRAMA $=$}

aprender, preciso ser mais paciente e entender que ninguém aprende igual e aceitar que a indisciplina existe, mas pode ser contornada".

Predomina uma projeção de ação para a disciplina, não necessariamente para o agir docente. Apenas no discurso de Viviane temos colocações que remetem a esse agir mais amplo para a profissão e não para o desempenho profissional. Entretanto, nos relatórios do ano seguinte desses alunos essa questão não é retomada. Como não são colocadas explicitamente na autoavaliação, não é possível confirmar se a experiência anterior teve efeito na prática de estágio seguinte, ou mesmo se esses apontamentos foram incorporados.

Quanto à compreensão do conhecimento de si mesmo, nota-se uma projeção do profissional que se almeja ser no futuro, bem como a consciência do contexto mais amplo, no qual ser-professor está inserido. Observemos alguns trechos:

- EDUARDO ( $3^{\circ}$ ano): Ainda tenho muito que melhorar para me tornar um docente de sucesso, mas são estas experiências que me faz crescer, para que eu me desenvolva cada dia mais e um dos fatos que marcaram bastante todas essas fases, foi que eu consegui vencer o medo e a timidez dentro e fora da sala de aula. (grifos nossos)

- EDUARDO (4 ano): [...] o estágio ultrapassa um modesto cumprimento de obrigações acadêmicas. Ele permite nosso crescimento e desenvolvimento pessoal, e que futuramente formará a nossa identidade como professor, também é uma maneira de interação entre a Universidade, a escola e a comunidade. (grifos nossos)

- BENícIO (3ano): Apenas no terceiro ano da graduação tomei consciência de que estava estudando para me formar professor. Claro que isso deveria ser óbvio para quem está fazendo qualquer licenciatura, mas durante os dois primeiros anos do curso eu não conseguia visualizar a parte prática da profissão e tinha muito medo de Metodologia e de Estágio. Toda vez que eu estava lá [sala de aula], pensava no quão significativa é a profissão de professor. Agradeço pela oportunidade que tive, por me colocar no mundo com os pés no chão e me fazer refletir sobre tantas coisas, principalmente naquilo que quero para mim e para minha vida. (grifos nossos)

Sob a luz desta análise, a descoberta da identidade docente ou a reafirmação dessa identificação pode nascer ou ser reforçada, em especial, nas disciplinas mais práticas do componente curricular ou mesmo nas atividades de estágio in loco. Essa ação reflexivoidentitária contribui para o seu saber-fazer, afinal, ao citar Houssaye (1995, p. 28), Pimenta (2012, p. 28, grifo da autora) relembra: "A especificidade da formação pedagógica, tanto a inicial como a contínua, não é refletir sobre o que se vai fazer, nem sobre o que se deve fazer, mas sobre o que se faz". Nesse sentido, ao olharem analiticamente para a própria práxis, exercitam a reflexão como princípio formativo na docência, o que pode promover o olhar crítico, consoante ilustram os fragmentos que seguem.

- CECÍlIA (4 ano): Antes do contato com a regência no Edhucca, eu ainda tinha dúvidas quando ao ser professor, principalmente pela má experiência no ano anterior, porém, após passar por esse campo hoje já me considero professora e tenho certeza que fiz a escolha certa. (grifos nossos)

Sobre Ser professor - Me vejo como professor, me sinto como professor e pretendo exercer essa profissão. Ser professor é além de estar à frente de uma sala de aula, é cuidar dos demais, é se preocupar, é sempre se adaptar e fazer o melhor. (grifos nossos) 


\section{$=$ TRAMA $=$}

- MILENA ( $4^{\circ}$ ano): O estágio supervisionado contribuiu muito com a minha formação humana e profissional. Através do estágio pude aprender muito sobre a realidade de uma sala de aula e como o sistema de ensino funciona na prática. (grifos nossos)

- ELENA (4⿳a ano): Por fim, acredito que ser professor é uma profissão que exige muito esforço, preparo, conhecimento, pesquisa, tempo e dedicação, tendo como objetivo ensinar e contribuir com o crescimento de vários alunos. Portanto, é algo que me faz bem desde 2011 (Curso de Formação de docentes) até hoje e quero continuar fazendo a diferença na vida dos alunos. (grifos nossos)

A construção do professor como sujeito crítico e reflexivo perpassa a compreensão autônoma do próprio dizer, bem como do discurso alheio. Assim, as ações são guiadas por objetivos axiológicos a partir dos quais se constrói a própria subjetivação identitária. Ao assumirmos a teoria bakhtiniana como suporte para o trabalho com a escrita, no processo autoavaliativo dialógico, acreditamos ser possível ampliar e fortalecer a interação do sujeito com o outro por meio do confronto ideológico veiculado através dos diversificados gêneros do discurso, afinal, é na interação com o outro que posições valorativas são tensionadas e o olhar crítico pode ser ampliado. É nesse processo de aproximação/refutação do discurso do outro, dos saberes já sistematizados e das experiências pessoais, que são refletidos e refratados os saberes e valores pessoais. Ilustramos com as considerações de Cássia, na autoavaliação do $4^{\circ}$ ano: "O estágio para mim foi muito significativo e trouxe muito aprendizado, me vi como aluna e ao mesmo tempo como educadora e entendi em parte essas duas realidades. [...] Após os estágios concluídos tive a certeza que é essa a profissão que realmente quero seguir, é trabalhoso, exige tempo, paciência, compreensão e nem tudo sai perfeito, mas o resultado final é gratificante e vai além de ser um professor que apenas transmite o conhecimento. Enquanto educador o que é necessário para dar sentido ao ensino-aprendizagem para os alunos e fazerem refletir sobre a importância do conteúdo para a vida deles, compreendendo que se faz necessário ressignificar o processo de aprendizagem e não olhar para o meu aluno apenas como tal, mas como um ser humano que tem dificuldades, que comete erros, que acerta e que tem uma bagagem de conhecimento e cultura para ser explorado e aprimorado" (grifos nossos).

A autocrítica pode/deve ampliar a compreensão do mundo ao redor do sujeito. Mesmo com ocorrências insuficientes, trata-se de um posicionamento explicitado por Cássia, um dizer autônomo e consciente pelos seguintes motivos: a) a identificação com a profissão "tive a certeza que é essa a profissão que realmente quero seguir", com a consciência de um trabalho árduo "é trabalhoso, exige tempo, paciência, compreensão e nem tudo sai perfeito, mas o resultado final é gratificante e vai além de ser um professor que apenas transmite o conhecimento."; b) a identificação com determinada perspectiva do papel docente ao afirmar que ser professor vai além da transmissão do conhecimento, a quem compete ressignificar o processo de aprendizagem; e c) a compreensão do outro (aluno) como sujeito autônomo e detentor de saberes.

Na contramão dessa autonomia crítica de mundo, tem-se, nas produções destacadas, em linhas gerais, o reflexo de uma tradição educacional voltada para um pensamento hegemônico, a qual durante séculos voltou-se para a reprodução e não para a interpretação dos conhecimentos. Retoma-se, por exemplo, a colocação de um "crescimento e desenvolvimento pessoal, e que futuramente formará a nossa identidade como professor" (Eduardo, $4^{\circ}$ ano). Não se "é professor" durante a formação inicial; essa identificação somente será efetivada na atuação em sala de aula, na prática in loco. Sob essa ótica, os pensamentos ainda condicionam reflexos dessa prática, limitando-se a reproduzir os conhecimentos sistematizados sem questioná-los, compreendê-los ou mesmo, reconhecê-los, o que não 


\section{$=$ TRAMA $=$}

convida o sujeito aprendiz a assumir-se como sujeito autônomo. O trabalho com o gênero autoavaliação evidencia um processo de escrita em que se sobressai a posição discursiva e crítica dos licenciandos, bem como seus valores axiológicos a respeito da profissão e dos saberes profissionais que podem perpassar a práxis docente.

\section{CONSIDERAÇÕES FINAIS}

Este texto teve como objetivo analisar se a discursividade crítica mobilizada e construída na produção da autoavaliação contribui para uma formação reflexiva. Para tanto, questionamos se (a) os procedimentos avaliativos na formação docente inicial podem contribuir para uma postura reflexivo-crítica mais consciente e inovadora e se (b) a compreensão da própria prática como estagiário (professor em formação) e como sujeito em atuação (professor do/no estágio) revela uma reflexão crítica do professor em formação.

O percurso teórico-metodológico empreendido demonstrou que a autoavaliação é um instrumento formativo que pode potencializar as práticas reflexivas, uma vez que possibilita o olhar para si mesmo e para um contexto mais amplo, que situa as práticas individuais em um sistema de ensino que se constitui de fatores sociais, históricos, culturais e políticos. Isso posto, a atividade de escrita, de modo particular, nesta pesquisa, a escrita na formação docente, não constitui uma mera atividade acadêmica; ao contrário, deve ser compreendida como um espaço de reflexão de um [...] "sujeito ativo, deliberado, consciente nas práticas de linguagem, que reflete e opera sobre a língua em uso para demarcar atitudes responsivas próprias tanto na leitura quanto na produção textual" (POLATO, 2017, p. 100-101).

Não obstante a produção de textos seja um caminho para o processo reflexivo, a análise das autoavaliações demonstrou que houve falhas no objetivo formativo do instrumento, uma vez que as reflexões poderiam incidir mais a respeito das relações sociais e os valores que definem e sustentam os saberes e as práticas docentes. Assim, o estudo nos permite refletir sobre nossas práticas como professoras formadoras, já que uma das possibilidades observadas é a necessidade de adequar os critérios elencados no roteiro oferecido aos alunos para o desenvolvimento da atividade, objeto de um novo estudo e, consequentemente, de um novo agir docente.

$\mathrm{Na}$ formação docente inicial ou continuada, a perspectiva crítico-reflexiva visa à construção de meios e instrumentos para a promoção de um conhecimento que auxilie a ação docente autônoma e consciente, de modo a promover um agir docente mais significativo e comprometido. No exercício da docência reflexiva, formar um profissional crítico significa formar um professor que sabe fazer, sabe explicar o que faz e tem consciência do porquê faz, ou seja, um sujeito que sabe seu papel social e o valora consoante suas relações socioideológicas. Sob essa ótica, a prática da autoanálise por meio da escrita autoavaliativa permite compreender os fatores que endossam o próprio agir e, consequentemente, que contribuem para orientar a ação pedagógica na busca pelo aperfeiçoamento profissional.

\section{REFERÊNCIAS}

BAKHTIN, Mikhail. Os gêneros do discurso. Organização, tradução, posfácio e notas de Paulo Bezerra. São Paulo: Editora 34, 2016.

COSTA-HÜBES, Terezinha da Conceição. Prática de análise linguística no ensino fundamental e sua relação com os gêneros discursivos. PERcursos Linguísticos, Vitória (ES), v. 7, n. 14, 2017, p. 270-294.

ECKERT-HOFF, Beatriz Maria. Escritura de si e identidade: o sujeito-professor em formação. Campinas, SP: Mercado de Letras, 2008.

FONTANA, Maire Josiane; FÁVERO, Altair Alberto. Professor reflexivo: uma integração entre teoria e prática. REI - revista de Educação do IDEAU, v. 8, 2013, p. 1-14. 


\section{$=$ TRAMA $=$}

FREIRE, Maximina M.; LEFFA, Vilson J. A auto-heteroecoformação tecnológica. In: LOPES, Luiz Paulo da Moita (org.). Linguística Aplicada na modernidade recente: festschrift para Antonieta Celani. São Paulo: Parábola Editorial, 2013, p. 59-78. (Lingua[gem]; 55)

GHEDIN, Evandro. Professor reflexivo: da alienação da técnica à autonomia da crítica. In: PIMENTA, Selma Guarrido; GHEDIN, Evandro (orgs.). Professor reflexivo no Brasil: gênese e crítica de um conceito. 7 ed. São Paulo: Cortez, 2012, p. 129-150.

LIBÂNEO, José Carlos. Reflexividade e formação de professores: outra oscilação do pensamento pedagógico brasileiro? In: PIMENTA, Selma Guarrido; GHEDIN, Evandro (orgs.). Professor reflexivo no Brasil: gênese e crítica de um conceito. 7 ed. São Paulo: Cortez, 2012, p. 53-79.

MELO, Kelly Cristina Marigliani. Modalidades de Avaliação da aprendizagem e suas relações com o ensino/aprendizagem de português língua materna. 2009. Dissertação (Mestrado). Universidade Federal do Pará, Instituto de Letras e Comunicação, Curso de Mestrado em Letras, Belém, 2009.

MILLER, Inés Kayon de. Formação de professores de línguas: da eficiência à reflexão crítica e ética. In: LOPES, Luiz Paulo da Moita (org.). Linguística Aplicada na modernidade recente: festschrift para Antonieta Celani. São Paulo: Parábola Editorial, 2013, p. 99-121. (Lingua[gem]; 55)

NUNZIATI, Georgette. Pour construire um dispositif d'évaluation formatrice. Cahiers pédagogiques, Paris, 280, 1990.

PIMENTA, Selma Garrido; LIMA, Maria Socorro Lucena. Estágio: diferentes concepções. In.: Estágio e docência. 7. ed. São Paulo: Cortez, 2012, p. 31-57. (Coleção docência em formação - Série saberes pedagógicos)

PIMENTA, Selma Garrido. Formação de professores: identidade e saberes da docência. In: PIMENTA, Selma Garrido. (Org). Saberes pedagógicos e atividade docente. São Paulo: Cortez Editora, 2012, p. 15-38 POLATO, A. D. M. Análise linguística: do estado da arte ao estatuto dialógico. Tese (Doutorado em Linguística Aplicada) - Programa de Pós-graduação em Letras, Universidade Estadual de Maringá - UEM. Maringá, p. 230. 2017.

SACRISTÁN, José Gimeno. Tendências investigativas na formação de professores. In: PIMENTA, Selma Guarrido; GHEDIN, Evandro (orgs.). Professor reflexivo no Brasil: gênese e crítica de um conceito. 7. ed. São Paulo: Cortez, 2012, p. 94-102.

SCHÖN, Donald. Formar professores como profissionais reflexivos. In: NÓVOA, Antônio (org.). Os professores e sua formação. Lisboa: Dom Quixote, 1992, p. 77-91

SCHÖN, Donald. Educando o Profissional Reflexivo: um novo design para o ensino e a aprendizagem. Trad. Roberto Cataldo Costa. Porto Alegre: Artmed, 2000.

TARDIF, Maurice. Os professores diante do saber: esboço de uma problemática do saber docente. In: Saberes docentes e formação profissional. 17 ed. Petrópolis, RJ: Vozes, 2014.

VALADARES, Juarez Melgaço. O professor diante do espelho: reflexões sobre o conceito de professor reflexivo. In: PIMENTA, Selma Guarrido; GHEDIN, Evandro (orgs.). Professor reflexivo no Brasil: gênese e crítica de um conceito. 7 ed. São Paulo: Cortez, 2012, p. 215-232.

ZEICHER, Kenneth. El maestro como professional reflexivo. Cuadernos de Pedagogia, n. 220, 1992. p. 44-49.

Recebido em 11-02-2021

Revisões requeridas em 14-04-2021

Aceito em 01-05-2021 